\title{
Promoting Mental Health in School-Young People from Scotland and Sweden Sharing Their Perspectives
}

\author{
Catrine Kostenius $^{1}$ (D) - Sebastian Gabrielsson ${ }^{1} \cdot$ Eva Lindgren $^{1}$
}

Published online: 26 December 2019

(C) The Author(s) 2019

\begin{abstract}
The rate of mental ill health has increased among children and youth during the past decade in Scotland and Sweden. School is important in influencing both health and education. The starting point for health promotion in school involves those who are affected, the students. The aim of this study was to describe and understand how mental health can be promoted in school from the perspective of young people. A total of 14 Scottish and Swedish young people aged 15-21, 11 girls and 3 boys from 3 municipalities, participated in 4 focus groups. The phenomenological analysis resulted in one main theme: Everyone is being there for each other encompassing three themes without any relative order of precedence: being in a safe, inclusive, and well-informed space; meeting adults who are available, listening, and taking action; and feeling significant and being of significance to others. Based on these findings, we suggest the following aspects to be essential when aiming to promote mental health in schools: (1) value and appreciate young people's experiences, (2) view everyone in school regardless of age or profession to be an important piece in the mental health promotion puzzle by adopting a "whole school approach," (3) foster a listening culture that focuses on building enabling relationships, (4) promote health and learning simultaneously to increase health literacy, (5) educate about mental health to minimize stigma and increase confidence in taking appropriate action.
\end{abstract}

Keywords mental health $\cdot$ youth $\cdot$ qualitative

In order to secure a future generation of well-educated young people in good health, schools need to handle the challenge of mental ill health, which is a growing problem in children and youth in a wide variety of regions and countries (WHO 2018a). Mental ill health has increased among children and youth during recent decades in Scotland and the rest of the UK. Longstanding mental health conditions have increased in children and young adults aged 4-24, in

Catrine Kostenius

catkos@1tu.se 
England 0.8-4.8\% over 19 years, in Scotland 2.3-6.0\%, over 11 years, and in Wales 2.6-4.1\% over 7 years (Pitchforth et al. 2018). In Scotland, a substantial increase in self-reported mental issues in the youth is believed to have broad negative impacts on young people's well-being, health, and education (Collishaw 2015). Sweden has faced a similar development. A significant portion of Swedish students aged 10-18 requires mental health support as one in five suffer from mental disorders, and problems are more prevalent in students aged 16-18 (OECD 2013). The proportion of 13- and 15-year-old girls and boys in Sweden who report recurrent psychosomatic symptoms has doubled since the mid-1980s (Public Health Agency of Sweden 2018). In 2013/2014, over half of the 15-year-old girls and nearly one-third of boys of the same age reported psychosomatic symptoms (Public Health Agency of Sweden 2018). According to the Public Health Agency of Sweden (2018), young people in Sweden today feel increasingly stressed and pressured to achieve qualifications for higher education and the labor market. Further, Hagquist (2015) reports that adolescents self-reported psychosomatic problems are worse compared with other Nordic countries, and this applies to both younger and older adolescents. The Public Health Agency of Sweden suggests that a positive learning environment in school might be the most effective intervention to promote mental well-being and to prevent mental ill health in children and young people. The World Health Organization (WHO 2018b) argued the importance of school in influencing both the health and education of future generations. Eriksson (2019) suggests that interventions between the individual, the organizational, and the structural level are required in order to reverse the trend of mental ill health, and advocates an approach involving the entire school's organization. While a reluctance to combine the results of health research with educational programs exists (Mohammadi et al. 2010), both Swedish and Scottish policy specify the reciprocal relationship between health and education: The Swedish National Agency for Education (2011) states that schoolchildren's well-being and development should be a focus in schools, and health and lifestyle issues are to be addressed. The Swedish National Board of Health and Welfare and Swedish National Agency for Education (2016) highlight that student health care staff are to contribute to health promoting school development and to eliminate obstacles for individual students' learning. The Scottish policy framework getting it right for every child (GIRFEC) remarks on the necessity of placing the child and family at the center in order to improve children's well-being via early intervention, universal service provision, and multiagency coordination across organizational boundaries (Coles et al. 2016).

Uncertainty surrounds the concepts of mental health and mental ill health (Bremberg and Dalman 2015). In this paper, we recognize mental health as one aspect of the holistic view of health used in health promotion. This is described by the World Health Organization (WHO 1998) as "fostering physical, mental, social and existential health" (p.8). We agree with a definition of mental health as "a state of well-being in which the individual realizes his or her own abilities, can cope with the normal stresses of life, can work productively and fruitfully, and is able to make a contribution to his or her community" (WHO 2007, p.1). We further define mental ill health according to the European Commission (2005) as "a condition that includes mental health problems and strain, impaired functioning associated with distress, symptoms, and diagnosable mental disorders" (p.1). Additionally, the focus in this study is positive mental health, which according to Tamminen et al. (2016) is one of the key attributes of mental health promotion.

School is a suitable arena for promoting health and learning simultaneously, and health literacy is considered a competence that an individual needs in order to live a healthy and prosperous life (Backman et al. 2012; Kickbusch et al. 2006). The "whole school approach" is 
about combining health and well-being with learning in school and includes students and all school staff in the process (Moynihan et al. 2016; Rowling 2009). Wyn et al. (2000) noted that this approach challenges educational staff to be comfortable and confident in promoting mental health. The whole school approach fits well with the intersectoral multi-strategy course of action that is suggested in the World Health Organization's (WHO 1986) definition of health promotion as "the process of enabling people to increase control over, and to improve, their health" (p.1). Further, the organization communicates the seven principles of health promotion: empowering, participatory, holistic, intersectoral, equitable, sustainable, and multi-strategy (WHO 1998).

Young people with an active interest in mental health promotion demonstrate a desire to be involved, and researchers need training on how best to actively and meaningfully involve young people in mental health research (Mawn et al. 2015). This cooperative and participatory approach with young people is echoed in the body of work on student voice (see, for example, Bergmark and Kostenius 2018; Cook-Sather 2006; Mitra and Serriere 2012). Student voice goes beyond receiving input from students, also allowing young people to share their opinions on school issues with administrators and faculty. The youth may even assume leadership roles in partnership with school staff in efforts to bring about change (Mitra 2009). Student voice activities can contribute to school reform in general, and especially with regard to students' learning and achievement (Peacock 2006).

As mentioned above, the rate of mental ill health has increased among children and youth during the past decade in Scotland and Sweden (Pitchforth et al. 2018; Collishaw 2015; OECD 2013; Public Health Agency of Sweden 2018). Giving voice to young people living in these two countries may give us more knowledge about how mental health can be promoted in school. Therefore, the aim of this study was to describe and understand how mental health can be promoted in school from young people's perspectives.

\section{Method}

Because young people can be considered to be experts on their own everyday experiences and preferences, it is vital to give voice to the ones that it is all about - the young people - in order to involve them in research that concerns questions about their health and well-being (Bergmark and Kostenius 2009). We used focus groups to enable the young participants to voice their experiences, discuss the topic, and argue their opinions regarding how mental health can be promoted in school inspired by Myers (1998) and Chatrakul Na Ayudhyaa et al. (2014). Analyses were based on phenomenological analysis described by van Manen (1990) to capture the phenomenon of lived experience. In phenomenological research, lived experience is the starting point and end point and is considered to be "our immediate, pre-reflexive consciousness of life" (p.35). Further, according to van Manen (1990), the "aim is to transform lived experience into a textual expression of its essence - in such a way that the effect of the text is at once a reflexive re-living and a reflective appropriation of something meaningful: a notion by which a reader is powerfully animated in his or her own lived experience" (p.36).

\section{Participants}

A total of 14 Scottish and Swedish young people with experiences of mental ill health aged 15-21 (11 girls and 3 boys) from 3 municipalities participated in 4 focus groups. Participants 
in Scotland were recruited through a voluntary association with the aim to enable children and young people facing challenges to have their voices heard, and 8 young people ( 6 girls and 2 boys) agreed to partake in the study. In Sweden, participants were recruited through a youth group organized by the student health team in collaboration with the regional County Council, and a youth group organized by a Christian congregation. A total of 6 young people ( 5 girls and 1 boy) agreed to participate in Sweden, 3 from each youth group.

\section{Ethics}

The researchers gave all participants oral and written information about the study before the workshop, as outlined in the Helsinki Declaration (World Medical Association 2015). All participants were over the age of 15 and made up their own mind about participation; however, an informational letter was made available to their parents. Voluntary participation and confidentiality was explained, and before the study started, it was reviewed by the regional ethical committee (2017/220-31).

\section{Data Creation}

Two focus groups were held in Scotland by a staff member at the Scottish voluntary association, and two focus groups were held in Sweden by the first and third authors who all were moderators and took field notes. In order to capture the participating young people's experiences, thoughts, and ideas, they received two assignments: the dream exercise and the heart exercise. They were first presented with the dream exercise in which they were asked to discuss the following question: What does a "mentally healthy" school look like? They were encouraged to use the provided large-size flipchart and colored pens to draw pictures together while answering the question. Similar to the dream exercise, the participants were invited to take part in the heart exercise focusing on the following question: What should be the values, ethos, culture, and "feeling" of a mentally healthy school? They were once more encouraged to use the flipchart and colored pens to draw pictures together while answering the question.

After the two exercises were completed, the participating young people were presented with an overall question: How can schools promote mental health and have a role in supporting early intervention in children and young people with emotional and mental health problems? The drawings were the point of departure in the focus group discussions that followed. During the discussion, the drawings made in the exercises were re-visited several times in order to help the participating young people elaborate on how mental health can be promoted in school.

\section{Analysis}

The focus group interviews from Scotland were transcribed verbatim by a staff member at the Scottish voluntary association, and the second author transcribed the Swedish focus group interviews. Field notes were transcribed by the first author. Data consisted of the transcribed focus group interviews, drawings from the assignments, and field notes, which were all seen as a whole. The phenomenon in this study was the young people's reflections and their ideas on how mental health can be promoted in school. According to van Manen (1990), phenomenological analyses can be described as passing through different phases of reflectively appropriating, of clarifying, and of making explicit the structure of meaning of the lived experience. In the first phase, reflectively appropriating, we considered all the data material as a whole, which 
gave an overall view of the young people's lived experience. In the second phase, clarifying, we read all the text and viewed the drawings once again making notes on similarities and differences and how different statements connected to each other. The first two phases were done individually by all authors, which resulted in three different descriptions of the data material with preliminary constructs. In the third step, making explicit the structure of meaning of the lived experience, the three authors' preliminary constructs were combined into one mind-map creating themes to explain the collective understanding of the data. Each theme encompassed variations of the young peoples' experiences, reflections, and ideas on how mental health can be promoted in school. We challenged our own understanding of the data by discussing with each other and making our own professional pre-understandings explicit as a pediatric nurse and health educator (first author) and mental health nurses (second and third author). Although our aim was to achieve a holistic understanding of the young people's lived experiences on a group level, we valued and elucidated young people's subjective experiences and choose quotes to exemplify aspects of the findings.

\section{Findings}

\section{Everyone is Being There for Each Other}

The phenomenological analysis resulted in one main theme: Everyone is being there for each other that consists of three themes without any relative order of precedence: being in a safe, inclusive, and well informed space; meeting adults who are available, listening, and taking action; and feeling significant and being of significance to others. The young people shared their experiences of how mental health, visions, and ideas on how mental health can be promoted in school using personal stories, focus group discussions, and drawings. We choose one drawing to exemplify the main theme Everyone is being there for each other (Fig. 1). This drawing exemplifies the young people's thoughts on what actions and attitudes that should prevail in school in order to promote mental health, making explicit that this can be achieved when everyone, students and staff alike, is being there for each other.

The themes are described in more details below:

\section{Being in a Safe, Inclusive, and Well-Informed Space}

The young people's narratives revealed the need for school to be a safe and inclusive space. The following is a discussion which took place among the young people in one of the focus groups with the young people:

“ - Our guidance [teachers] are lovely and they want to help, but they have a room where everyone can hear you and they want to help but the facilities are not always there.

- Some of the teachers actually have classes to teach, so they spend half of their time out teaching and when they are there, they have another year [of students] to look after, not just your year.

- I find that they want to refer you on so that you are not their problem - they've done their bit and passed you on and I can find this can be the case so it's not their responsibility." 


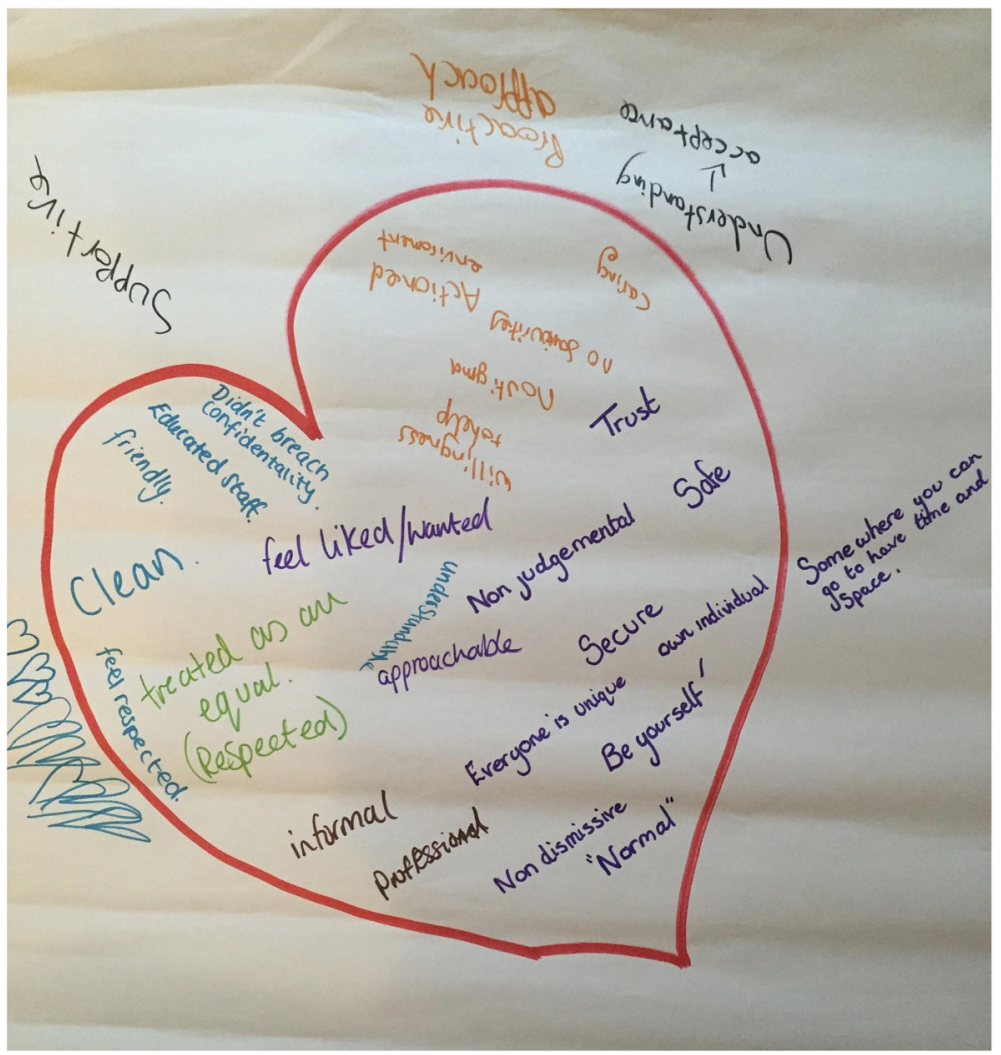

Fig. 1 This drawing was made by young people during the heart exercise in the focus group, which we have chosen to visualize the main theme everyone is being there for each other

According to the young people without relationships with the staff, the staff contributes to lack of trust and to confide in private matters is minimized. "I have never really gone to speak to my guidance teacher about any mental health stuff because I just don't feel comfortable so it might have been different had this relationship been built up from the first year, but I just didn't have it." A lack of confidentiality was noted as a negative aspect that refrains them from getting the help they needed. The young people narrated about the fear of being exposed.

"It sounds really stupid but our guidance [teacher] base is in the back of the school and we have to walk through everyone's concourse...everyone knows if you walk in that room....and everyone can see you come out...something's happened there."

The young people shared feelings of disappointment, resentment, and anger in connection to how they had been treated in school previously. They described school as a place where inequalities are built on instead of compensated for. "School is set up so that only some can succeed." Their feeling was that something must be wrong when mental health problems are increasing among young people. Further, the young people experienced that the student health service (SHS) and teachers lack knowledge and time to meet their needs of support. They 
described the importance of being seen, heard, and to be taken seriously when not feeling well, even if they are not able to articulate their feelings clearly. Unfortunately, the young people's experiences described a number of different occasions when these wishes were not realized.

"I had been crying and you could see that I wasn't feeling well ... but my defense mechanism is to be rude and then she said 'if that's your attitude then I don't have to help you' and then she just left. That night I was admitted to psychiatric care."

In addition, the young people wished that staff in school was more educated and confident in mental health issues. They argued that it should be as natural teaching about mental health in school as teaching and being educated in physical disorders. They were clear about the need for knowledge in order to increase confidence regarding how to handle mental health issues. The young people also described knowledge as part of the solution to overcome the stigma of mental health issues. They suggested that all staff in school and all students need to be educated about mental health.

"If someone has diabetes ... Okay, tell me if you get a little dizzy, I'll make sure you get something to eat or if you have lactose ... Okay, I will not serve you milk. But if someone has depression or other mental health problems then people act like ... what should I do, what if I'm wrong and she goes and jumps in front of a car ..."

In the young people's negative descriptions of school, there was a built-in notion of wanting the opposite. Feeling unsafe revealed a need for safety. Experiences of exclusion revealed the need for inclusion, and the lack of knowledge about mental health issues revealed the need for education. The young people agreed that school can promote mental health and have a role in supporting early intervention in children and young people with emotional and mental health problems. "You spend all your teenage years at school and you spend most of your day there so it's good if ...people [are] aware of mental health issues and break down the stigma of it too as that's a massive part of it and why people don't go and get help as well." They shared a vision of a school where they could feel safe, be respected, included, and accepted for who they are. The young people's narration of a "dream come true" scenario included encounters in which they encounter a space where, as one young person said, "there is no stigma."

\section{Meeting Adults Who are Available, Listening, and Taking Action}

According to the young people, adults who are available, listening, and taking action are important for promoting mental health in school. The young people experienced that the school of today is in great need of improvement when it comes to social and caring competences to manage early intervention. The following discussion took place among the young people in one of the focus groups:

“- There should be someone who takes the time to actually listen...

- I experienced that when I went to middle school, second grade I think, and I said to my friends that I wanted to kill myself ... these friends told their parents who contacted the school ... the only thing school did was to call my Dad and he said, that's just how she is and then I got to talk to the social worker and then it was forgotten, I got no more help. 
- It was in second grade?

- Yea, so how old were you then? Eight, nine? Aaaa they did not take you seriously...and it was really serious from your perspective.

- I was eight and I did not succeed to kill myself, but if I would have received help then I would probably not be here today talking about my mental problems."

Their descriptions of non-satisfying encounters with adults or a general lack of adults being present included feelings of not being important enough to be cared for or not being prioritized. The young people experienced that school staff were not available when they were in need of help. The lack of support was on an individual level as well on a structural level. "Our mental health nurse visited about twice in the first year and then left and we didn't have one. Well, I'm sure we do, but it's only one person against the world so if you are trying to get help it's like well come back in a month when she's here and we can see what we can do." The young people described feeling abandoned and left to solve problems on their own. Talking with an adult that the young person felt comfortable to confide in was not always possible. "I'm a guy and it seems silly but I feel uncomfortable talking to a girl about my problems. It was kind of if I had a problem there wasn't anyone for me to go to and I couldn't just walk up to any teacher." The young people described their experiences with parents and how, for instance, their discussions at dinner were helpful. One young person suggested "Parents listen to your children, they need to be heard, take time to listen."

The young people described a need to talk with someone who connects with them and is able to be listened to and comforted when sad. 'If someone says I'm not feeling well it doesn't matter if you're in the middle of a depression or plan to kill yourself tomorrow or maybe you just need a hug or someone who listens for ten minutes and then you can move on with your life." One young person concluded "[I] need a hug or someone who listens." The art of listening was elaborated on by the young people and was described as a human encounter that is driven by caring action. One young person wanted that adults act "...like they actually want to do it and not just be part of their job. They're not just doing it to get paid." Issues connected to the act of listening that were brought up by the young people were "confidentiality" and "freedom of choice," "To feel free to speak to any teacher, not just guidance [teachers]. To not be passed on where possible," and "Schools [need] to listen to your needs and act on them. No matter what sexuality, gender, ethnicity etcetera, they should not brush it off for that reason."

The young people connected being educated and well-informed about mental health issues as a prerequisite for being a good listener. They stressed the connection of education and listening with the changes in how mental health issues are viewed.

"The reason I think a lot of adults these days don't listen or believe in it is because they probably didn't get an education on it, so they don't understand it. If you understand [mental health issues] from a young age, then you are not going to grow up and have the same stigma that adults do."

According to the young people, it is important to view mental health problems with openness and caring. They wished to meet adults who understand the severity of mental illness and the challenges that can be encountered. "It's a life threatening disease but they don't take it seriously." The young people described that other than meeting an adult who listens and cares for them, the adult should also take action. They narrate about when action was initiated and carried through, as well as when action lacked action. Suggestions for developing an 
understanding about mental health issues and developing an action competency included education and viewing the topic as a natural phenomenon. The young people stress the connection between increased knowledge and doing something with the knowledge. "[When] you encounter someone with suicidal thoughts ... do not keep their secret ... seek help." One young person shared experiences of an adult taking action and the insight of how important it was, "I was angry, I hated her the first few days... then I realized that she actually saved my life."

\section{Feeling Significant and Being of Significance to Others}

According to young people's experiences, feeling significant and being of significance to others were important for mental health in school. To enable this, young people expressed the importance of being accepted and respected for who they are. They pointed out that it was equally important to meet others with acceptance and respect. Their experiences included not being seen and listened to by friends and adults in school. For them, to be recognized and taken seriously by adults at school if they did not feel well required that they display and talk about how they felt with the right person, at the right time, and in a proper manner.

"We had a school nurse, and in the next room there was a counselor belonging to another program. But if you went to her when the nurse was out she would say 'no, you should be talking to the nurse'. And if you replied 'But she's not here?' then it was like 'Well you're not my responsibility".

In relation to experiences of feeling significant and being of significance to others, the young people's narratives revealed social media as an integral part of their everyday school life. They described how social media pressured them to, as they put it, "fit in" and to "belong" in order to get as many followers and likes as possible. They narrated about how being scrutinized and judged was not exclusive to social media, but that social media made this form of bullying easier. According to the young people, being acknowledged on social media was a doubleedged sword because it was nice when liked by many, but the opposite when they did not receive enough attention from others. The following discussion took place among the young people in one of the focus groups:

“- If I post something and don’t get many likes you feel like... like a failure.

-You feel bad.

You feel like you have failed because you don't have a bunch of people saying oh you're so wise and clever or... nice or something..."

The young people described how social media could be supportive, making them feel significant, and cared for. One young person who had experienced sexual abuse described how she did not have to feel alone, "[I have] the support of an entire army who listens to me and doesn't call me a liar." Another young person described how having access to her smartphone during school hours meant that she did not need to feel alone during breaks. "I used to be bullied, and this was before when you weren't allowed to have your phone, but now I just plug in my earphones and I can sit in the hallway by myself and be with my friends." Additionally, social media was described as a source of information that could empower. One young person said that she had learned about the concept of "slut shaming" only through social 
media and believed that had helped her feel confident and not accept other people being judgmental about her sexuality.

The young people talked about how all adults and young people in school have a responsibility and that it is possible to recognize and intervene when someone is not feeling well. "I mean, if you see someone bleeding in the street you don't think that person is standing closer so I shouldn't help. You take some civic responsibility. Like taking care of each other." The young people also took it upon themselves to act if they learned that a friend was having mental health problems. This often meant turning to adults, either by helping or encouraging their friend to talk to an adult, or that they themselves alerted a parent or a teacher even if this meant breaking a confidence. Teachers taking action and interfering after being informed of bullying in relation to social media were perceived as positive, although the young people were questioned if this should be part of teacher's responsibility. In order to strengthen the feeling of being significant, the young people wished for a school that is supportive and adaptive to the needs of individual students, which would help in relieving some of the pressures they experienced.

\section{Discussion of Findings}

These findings describe young people's views and experiences of mental health issues in a broad sense, combining experiences related to serious mental illness, psychiatric care, and treatment with their thoughts about everyday psychological and emotional challenges. While these very different experiences seemingly reflect very different mental health needs of young people, we believe that this is not necessarily the case given the understanding that mental health is more than an absence of mental illness, which may or may not be consistent with a diagnosis (cf. Bremberg and Dalman 2015; WHO 1997). The young people in this study were clear about the need for increased knowledge about mental health in order to minimize the stigma and to increase confidence in taking appropriate actions to support mental health. In the same line of reasoning, the World Health Organization (WHO 1998) exclaims "There is no health without mental health" (p.1). We agree, fully aware that health is more than mental health, and support a holistic view of health and acknowledge physical, social, and existential health as well. Either way, the expressed need for education about mental health can be compared with the body of work on health literacy. According to the World Health Organization (WHO 2013), "health literacy entails people's knowledge, motivation, and competencies to access, understand, appraise, and apply health information to make judgments and take decisions in everyday life concerning health care, disease prevention, and health promotion to maintain or improve quality of life during the life course" (p.4). Additionally, Kickbusch et al. (2006) argue for including health literacy in the school curriculum because strategies to build health literacy must be viewed as a part of a lifelong learning and should start at a young age.

Based on principles of participation and empowerment, the starting point for health promotion in school involves those who are affected, in other words, the students (WHO 1986). According to Warne (2013), this is many times one of the most difficult principles to fulfill as the students are the primary target group of the school, but the interests of the school are primarily monitored by adult professionals. Thus, there is room for improvement if we focus on the empowering perspective where participation is key. If schools were to offer what our findings suggest, they ought to ensure a safe, inclusive, and well-informed space; adults who are available, listening, and taking action; and the experience of feeling significant and 
being of significance to others; this might go a long way in meeting the mental health needs of most young people. School is a large component of young people's lives that can facilitate or pose a barrier to youth mental health recovery (Kelly and Coughlan 2018). While we believe these findings reflect and support a health promotion perspective, they also align with a recovery perspective. According to Anthony (1993), the recovery model of mental health emphasizes recovery in mental health as a "deeply personal, unique process of changing one's attitudes, values, feelings, goals, skills, and/or roles” (p. 527). Recovery processes include connectedness, hope, identity, meaning, and empowerment (Leamy et al. 2011). This understanding of recovery has resulted in the development of mental health services that build on recovery principles that offer educational approaches as an alternative or complement to treatment (Anfossi 2017). Looking at mental health promotion from the perspective of young people, it becomes evident that health and learning cannot be separated, i.e., the young people in our study described how school should be a place for learning about mental health. From a recovery perspective, one can argue that school is also a place for learning about oneself and one's mental health. These findings can be compared with the argument by Wyn et al. (2000) for the "whole school approach," which combines health and learning, and well-being and school progress are linked. Additionally, this aligns with research that points out that school is the suitable arena for promoting health and learning simultaneously (Backman et al. 2012; Kickbusch et al. 2006). We echo the words of Young (2019), a university student and a member of the International Initiative for Mental Health Leadership: "The most important message I have, is that the time to talk about mental health is today" (p.75).

These findings indicate that young people have a wish for enabling relationships with adults, regardless of profession, in order to promote mental health. The theme meeting adults who are available, listening, and taking action can be compared with Bragg's (2007) argument for building a listening school culture and support the notion that it is not about the systems, but about relationships. While our findings indicate that both adults and young people in school have a potential to contribute to each other's mental health when everyone is being there for each other, we propose, from the perspectives of recovery and health promotion, that this should be understood as an interpersonal learning experience. Thus, our findings suggest that increased knowledge about mental health among both adults and young people in school can support young people in developing knowledge about themselves, and their own mental health by engaging in peer support and peer learning. This aligns with the student voice research by Cook-Sather (2006) and Kostenius and Bergmark (2016), which argued that we should view young people as experts in their own lives and appreciate and value their perspectives in school developmental processes. Another benefit from including everyone in the school arena is that staff and students alike have the increased ability to cooperate across professions. Based on these findings, we argue that we should take peer learning one step further to be not only about an exchange between students or staff, but more a sense of human-human, whether you are a student, a teacher, a janitor, a school nurse, etc. This can be compared with Peacock's (2006) discussion on school improvement ". . . underpinned by the ethic of everybody, trust and coagency demands that the whole community is given a voice and that dialogue takes place enabling progress that is both positive and enabling" (p.257). Hylander and Guvå (2017) recognized the need for a close cooperation between teachers and health care staff in schools, often called student health teams, as multi-professional cooperation that not only increases the health promoting efforts in school, but also changes the view of health and learning from separate to closely linked. Additionally, Viig and Fosse (2012) point out that there is a positive effect of learning through collaboration within schools. 


\section{Limitations and Discussion of Method}

The focus groups, in line with Myers (1998), gave the young people an opportunity to share their life experiences and voice their opinions, agreeing and disagreeing in discussions on how mental health can be promoted in school. According to Chatrakul Na Ayudhyaa et al. (2014) compared with individual interviews, the focus group method makes it possible to understand the persons in "the social and cultural context of their time...(p.159)", especially important as the purpose in this study was to discuss the school environment. Myers (1998) warns about pre-assumptions of the topic obstructing the broader understanding. However, the analysis gave a diverse picture of mental health promotion. One reason for this may be that the participants included young people with experiences of mental illness, not solely young people with mental health diagnoses. However, one limitation may be the oblique gender distribution with 13 girls and only 3 boys. The reason for this is unknown for us but might reflect genderrelated variations in the distribution of mental ill health. For example, the Public Health Agency of Sweden (2018) reported that over half of the 15-year-old girls but only nearly one-third of boys of the same age reported psychosomatic symptoms. The gender distribution in our study might also reflect gender-related differences in how mental ill health is communicated, suggesting that boys might be less prone to express mental ill health. No matter what the case may be, to receive a diverse picture of mental health promotion as possible, there should be an extra effort by mental health researchers to include both boys and girls. Additionally, an effort should be made to include groups in risk of mental ill health, for example, young migrants, LGBQ persons, and young people with disabilities (Gore et al. 2011; Shawel Abebe et al. 2014; Sundell Lecerof et al. 2016; Logie et al. 2016).

Pini (2002) argues for the potential of focus groups as empowering for participants. With this in mind, the moderators tried to create an open, calm, and trusting environment. With nopressure to perform, saying, for example, "there's no right or wrong answers or thoughts and it is up to each and every participant to decide what they want to share." Although the assignments were focused on how to promote mental health, the participant's focus was on negative experiences; this is evident in the themes. This in itself gives support to the reports and recent research, see, for example, Bremberg and Dalman (2015), Pitchforth et al. (2018), and Public Health Agency of Sweden (2018) regarding the need to prevent mental illness and promote mental health. The findings might be transferable to other contexts if subject to critical reflection.

\section{Conclusions and Further Research}

Finally, to conclude and propose practical applications based on the findings, we suggest the following aspects to be essential when aiming to promote mental health in school:

- value and appreciate young people's experiences

- view everyone in school, regardless of age or profession, as an important piece in the mental health promotion puzzle by adopting a "whole school approach"

- foster a listening culture that focuses on building enabling relationships

- promote health and learning simultaneously to increase health literacy

- educate about mental health to minimize stigma and increase confidence in taking appropriate action 
Based on the findings, we argue that the "whole school approach" should be further explored in order to pinpoint best practices to inform health promoting school development.

Acknowledgments First of all, we would like to thank the 14 young people from Scotland and Sweden participating in this study. Thank you to all the contact persons at the participating organizations for making this study possible. We appreciate the work of the Manager at the Highland Children's Forum, being the contact person in Scotland, holding focus groups, and transcribing the recordings.

Funding Information Open access funding provided by Lulea University of Technology. The study was partly funded by Northern Periphery and Arctic programme 2015-2018. Additionally, Riksbankens Jubileumsfond (the Swedish Foundations for Humanities and Social Science) enabled this study by their financing of the national Flexit research program. This study was also supported by Norrbottens Kommuner (Norrbotten Association of Local Authorities) and Luleå University of Technology, the Department of Health Sciences.

\section{Compliance with Ethical Standards}

Conflict of Interest The authors declare that they have no conflict of interest.

Ethical Approval The researchers gave all participants oral and written information about the study before the workshop, as outlined in the Helsinki Declaration (World Medical Association 2015). Voluntary participation and confidentiality was explained, and before the study started, it was reviewed by the regional ethical committee (2017/220-31).

Open Access This article is licensed under a Creative Commons Attribution 4.0 International License, which permits use, sharing, adaptation, distribution and reproduction in any medium or format, as long as you give appropriate credit to the original author(s) and the source, provide a link to the Creative Commons licence, and indicate if changes were made. The images or other third party material in this article are included in the article's Creative Commons licence, unless indicated otherwise in a credit line to the material. If material is not included in the article's Creative Commons licence and your intended use is not permitted by statutory regulation or exceeds the permitted use, you will need to obtain permission directly from the copyright holder. To view a copy of this licence, visit http://creativecommons.org/licenses/by/4.0/.

\section{References}

Anfossi, A. (2017). The current state of recovery colleges in the UK: final report. Implementing Recovery through Organizational Change (IMROC). http://imroc.org/wp-content/uploads/2017/12/The-current-stateof-Recovery-Colleges-in-the-UK1-1.pdf, accessed 30 January 2019.

Anthony, W. A. (1993). Recovery from mental illness: the guiding vision of the mental health service system in the 1990s. Psychosocial Rehabilitation Journal, 16, 521-538.

Backman, Y., Alerby, E., Bergmark, U., Gardelli, Å., Hertting, K., Kostenius, C., \& Öhrling, K. (2012). Learning within and beyond the classroom: compulsory school students voicing their positive experiences of school. Scandinavian Journal of Educational Research, 56, 555-570.

Bergmark, U., \& Kostenius, C. (2009). 'Listen to me when I have something to say' - students' participation in research for sustainable school improvement. Improving Schools, 12, 249-260.

Bergmark, U., \& Kostenius, C. (2018). Appreciative student voice model - reflecting on an appreciative inquiry research method for facilitating student voice processes. Reflective Practice, 19, 623-637.

Bragg, S. (2007). It's not about systems, it's about relationships: building a listening culture in a primary school. In D. Thiessen \& A. Cook-Sather (Eds.), International Handbook of Student Experience in Elementary and Secondary School (pp. 659-680). Dordrecht: Springer.

Bremberg S., \& Dalman C. (2015). Begrepp, mätmetoder och förekomst av psykisk hälsa, psykisk ohälsa och psykiatriska tillstånd hos barn och unga. Forskningsrådet för hälsa, arbetsliv och välfärd. https://forte. se/app/uploads/2014/12/kunskapsoversikt-begrepp.pdf, accessed 31 January 2019. 
Chatrakul Na Ayudhyaa, U., Smithson, J., \& Lewis, S. (2014). Focus group methodology in a life course approach - individual accounts within a peer cohort group. International Journal of Social Research Methodology, 17, 157-171.

Coles, M., Chenye, H., Rankin, J., \& Daniel, B. (2016). Getting it right for every child: a national policy framework to promote children's well-being in Scotland, United Kingdom. The Milbank Quarterly, 94, 334 365 .

Collishaw, S. (2015). Annual research review: secular trends in child and adolescent mental health. Journal of Child Psychology and Psychiatry, 56, 370-393.

Cook-Sather, A. (2006). Sound, presence, and power: student voice in educational research and reform. Curriculum Inquiry, 36, 359-390.

Eriksson, C. (2019). Mental health trends and the role of the school in adolescent health in the Nordic region. Health promotion i school settings. Stockholm: Nordic Welfare Center.

European Commission (2005). Green paper. Improving the mental health of the population. Towards a strategy on mental health for the European Union. European Commission. https://ec.europa.eu/health/ph determinants/life style/mental/green paper/mental gp en.pdf, .

Gore, F. M., Bloem, P. J. N., Patton, G. C., Ferguson, J., Joseph, V., Coffey, C., Sawywer, S. M., \& Mathers, C. D. (2011). Global burden of disease in young people aged 10-24 years: a systematic analysis. Lancet, 377, 2093-2102.

Hagquist, C. (2015). Unga in i Norden - psykisk hälsa, arbete, utbildning. Stockholm: Skolelevers psykiska hälsa. Nordic Center for Welfare and Social issues.

Hylander, I., \& Guvå, G. (2017). Elevhälsa som främjar lärande. Om professionellt samarbete $i$ retorik och praktik. Lund: Studentlitteratur.

Kelly, M., \& Coughlan, B. (2018). A theory of youth mental health recovery from a parental perspective. Child and Adolescent Mental Health, January 30, 2019: https://doi.org/10.1111/camh.12300.

Kickbusch, I., Wait, S., \& Maag, D. (2006). Navigating health. The role of health literacy, International Longevity Centre. https://ilcuk.org.uk/wp-content/uploads/2018/10/NavigatingHealth.pdf, accessed 30 January 2019.

Kostenius, C., \& Bergmark, U. (2016). The power of appreciation - an opportunity to promote health literacy in Swedish schoolchildren. Health Education, 116, 611-626.

Leamy, M., Bird, V., Le Boutillier, C., Williams, J., \& Slade, M. (2011). Conceptual framework for personal recovery in mental health: systematic review and narrative synthesis. The British Journal of Psychiatry, 199, $445-452$.

Logie, C. H., Lacombe-Duncan, A., Lee-Foon, N., Ryan, S., \& Ramsay, H. (2016). It's for us - newcomers, LGBTQ persons, and HIV-positive persons. You feel free to be: a qualitative study exploring social support group participation among African and Caribbean lesbian, gay, bisexual and transgender newcomers and refugees in Toronto, Canada. BMC International Health and Human Rights, 16, 18.

Mawn, L., Welsh, P., Kirkpatrick, L., Webster, L., \& Stain, H. (2015). Getting it right! Enhancing youth involvement in mental health research. Health Expectations, 19, 908-919.

Mitra, D. (2009). Strengthening student voice initiatives in high schools: an examination of the supports needed for school-based youth-adult partnerships. Youth and Society, 40, 311-335.

Mitra, D., \& Serriere, S. (2012). Student voice in elementary-school reform: examining youth development in fifth graders. American Educational Research Journal, 49, 743-774.

Mohammadi, N., Rowling, L., \& Nutbeam, D. (2010). Acknowledging educational perspectives on health promoting schools. Health Education, 110, 240-251.

Moynihan, S., Jourdan, D., \& Mannix Mcnamara, P. (2016). An examination of health promoting schools in Ireland. Health Education, 116, 16-31.

Myers, G. (1998). Displaying opinions: topics and disagreement in focus groups. Language in Society, 27, 85111.

OECD. (2013). Mental health and work: Sweden. Organisation for economic co-operation and development. Paris: OECD.

Peacock, A. (2006). Escaping from the bottom set: finding a voice for school improvement. Improving Schools, 9, 251-260.

Pini, B. (2002). Focus groups, feminist research and farm women: opportunities for empowerment in rural social research. Journal of Rural Studies, 18, 339-351.

Pitchforth, J., Fahy, K., Ford, T., Wolpert. M., Viner, R.M., \& Hargreaves, D.S. (2018). Mental health and wellbeing trends among children and young people in the UK, 1995-2014: analysis of repeated cross-sectional national health surveys. Psychological Medicine, January 29, 2019: https://doi.org/10.1017 /S003329171800175. 
Public Health Agency of Sweden (2018). Varför har den psykiska ohälsan ökat bland barnoch unga i Sverige? January 31, 2019: https://www.folkhalsomyndigheten.se/contentassets/628flbfc932b474f9503cc6f8e29fd45 /varfor-psykiska-ohalsan-okat-barn-unga-18023-2-webb-rapport.pdf, accessed 31 January 2019.

Rowling, L. (2009). Strengthening "school" in school mental health. Health Education, 109, 357-368.

Shawel Abebe, D., Lien, L., \& Harslof Hjelde, K. (2014). What we know and don't know about mental health problems among immigrants in Norway. Journal of Immigrant Minority Health, 16, 60-67.

Sundell Lecerof, S., Stafström, M., Westerling, R., \& Östergren, P.-O. (2016). Does social capital protect mental health among migrants in Sweden? Health Promotion International, 31(3), 644-652.

Swedish National Agency for Education (2011). Läroplan, examensmål och gymnasiegemensamma ämnen för gymnasieskola, 2011. https:/www.skolverket.se/undervisning/gymnasieskolan/laroplan-program-ochamnen-i-gymnasieskolan/laroplan-gy11-for-gymnasieskolan, accessed 31 January 2019.

Swedish National Board of Health and Welfare and Swedish National Agency for Education (2016). Vägledning för elevhälsan. http://www.socialstyrelsen.se/publikationer2016/2016-11-4, accessed 5 January 2019.

Tamminen, N., Sohlin, P., Barry, M., Kannas, L., Stengård, E., \& Kettunen, T. (2016). A systematic concept analysis of mental health promotion. International Journal of Mental Health Promotion, 18(4), 177-198.

van Manen, M. (1990). Researching lived experience. Human science for an action sensitive pedagogy. London: State University of New York Press.

Viig, N., \& Fosse, E. (2012). Leading and supporting the implementation of the Norwegian network of health promoting schools. Scandinavian Journal of Educational Research, 56, 671-684.

Warne, M. (2013) Där eleverna är. Ett arenaperspektiv på skolan som en steödjande miljö för hälsa. Doctoral thesis. Mid Sweden University, Sundsvall.

WHO (1986) The Ottawa charter for health promotion. World Health Organization. http://www.who. int/healthpromotion/conferences/previous/ottawa/en/index4.html, accessed 5 January 2019.

WHO (1997). Promoting health through schools: report of a WHO expert committee on comprehensivse school health education and promotion. World Health Organization. https://apps.who.int/iris/handle/10665/41987, accessed 30 January 2019.

WHO (1998). Health promotion evaluation: recommendations to policy-makers. World Health Organization. http://apps.who.int/iris/bitstream/handle/10665/108116/E60706.pdf?sequence=1, acceessed 5 January 2019.

WHO (2007). Mental health: strengthening mental health promotion. World Health Organization. http://mindyourmindproject.org/wp-content/uploads/2014/11/WHO-Statement-on-Mental-HealthPromotion.pdf, accessed 5 January 2019.

WHO (2013). Health literacy. The solid facts. Geneva: World Health Organization. available at: http://www.euro. who.int/_data/assets/pdf_file/0008/190655/e96854.pdf. Accessed 23 Dec 2019.

WHO (2018a). Global school health initiatives: achieving health and education outcomes. https://www.who. int/publications-detail/global-school-health-initiatives-achieving-health-and-education-outcomes accessed 29 November 2019.

WHO (2018b). Making every school a health promoting school. World Health Organization. https://www.who. int/activities/making-every-school-a-health-promoting-school accessed 28 Februarey 2019.

World Medical Association (2015). Declaration of Helsinki - ethical principles for medical research involving human subjects. World Medical Association. https://www.wma.net/wp-content/uploads/2016/11/DoHOct2008.pdf, accessed 5 January 2019.

Wyn, J., Cahill, H., Holdsworth, R., Rowling, L., \& Carson, S. (2000). MindMatters, a whole-school approach promoting mental health and wellbeing. Australian and New Zealand Journal of Psychiatry, 34, 594-601.

Young, B. (2019). In Hertzberg's Give young people a voice. Adolescent health in the Nordic region. Health promotion school settings. Nordic welfare center, Stockholm.

Publisher's Note Springer Nature remains neutral with regard to jurisdictional claims in published maps and institutional affiliations. 